
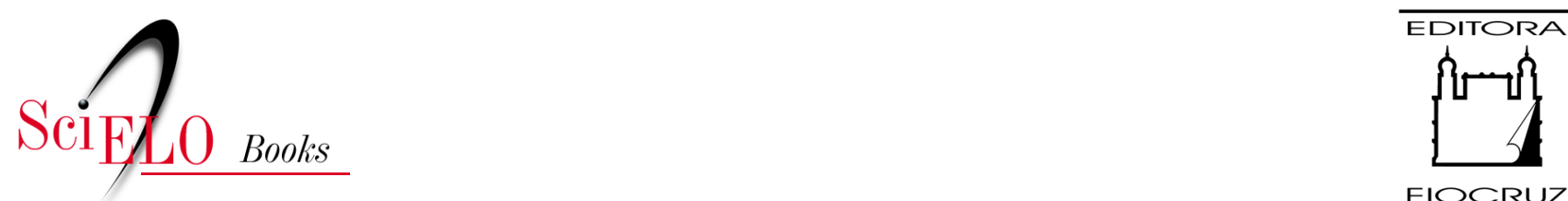

FIOCRUZ

\title{
Uma História do Dr. Luís Rey (fevereiro de 1989)
}

\author{
Virgínia Schall
}

\section{SciELO Books / SciELO Livros / SciELO Libros}

SCHALL, V. Uma História do Dr. Luís Rey (fevereiro de 1989). In: Contos de Fatos: histórias de Manguinhos [online]. Rio de Janeiro: Editora FIOCRUZ, 2001, pp. 67-76. ISBN: 978-85-7541-614-3. Available from: doi: $10.7476 / 9788575416143.0008$. Also available in ePUB from: http://books.scielo.org/id/hdq6f/epub/schall-9788575416143.epub.

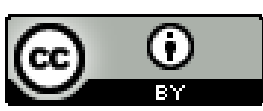

All the contents of this work, except where otherwise noted, is licensed under a Creative Commons Attribution 4.0 International license.

Todo o conteúdo deste trabalho, exceto quando houver ressalva, é publicado sob a licença $\underline{\text { Creative Commons }}$ Atribição 4.0. 


\section{Uma História do Dr. Luís Rey \\ (fevereiro de 1989)}

Como ébom a gente ter deixado a pequena terra
em que nasceu
E ter fugido para uma cidade maior, para
conhecer outras vidas...
Por toda parte sentir o segredo das coisas virus...
Manoel de Barros

$\mathrm{D}$

r. Rey é um parasitologista por excelência, autor de um dos livros mais completos na área, ${ }^{20}$ referência para pesquisadores e estudantes, assim como de um dicionário de termos médicos e biológicos que é uma verdadeira enciclopédia, contendo milhares de verbetes. ${ }^{21}$ É também um contador de histórias bem-humorado, que entremeia os casos com comentários sagazes e interessantes. Ao retornar ao Brasil, depois de dois períodos de exílio forçado por motivos políticos, veio morar no Rio de Janeiro. Era 1984 e eu, também chegada há pouco de Minas, ainda meio estrangeira no Rio, tive a oportunidade ímpar de estar com ele e sua esposa, Dora, num jantar em seu aconchegante apartamento. O primeiro contato que travei com o seu trabalho havia sido em 1978, quando eu desenvolvia

\footnotetext{
${ }^{20}$ REY, L. Parasitologia. Rio de Janeiro: Guanabara Koogan, 1991.

${ }^{21}$ REY, L. Dicionário de Termos Técnicos de Medicinae Saúde. Rio de Janeiro: Guanabara Koogan, 1999.
} 
minha tese de mestrado na Escola de Medicina da UFMG, em Belo Horizonte. Na fase de levantamento bibliográfico, encontrei um livro escrito por ele em 1956, uma verdadeira preciosidade sobre os moluscos vetores da esquistossomose, que foi, para o meu trabalho, uma das principais referências obtidas naquela época. ${ }^{22}$ Não imaginava sequer poder conhecê-lo, pois os créditos de edição do livro o datavam de um tempo em que eu apenas começava a andar, e a sabedoria expressa no livro me fez imaginá-lo um professor já idoso àquela época. Assim, foi uma alegria imensa encontrá-lo, anos mais tarde, robusto, saudável, jovial mesmo, cheio de entusiasmo e animação. Soube então que publicara o livro com trinta e poucos anos, ainda nos primeiros tempos de sua carreira.

Algumas outras vezes voltei à casa do Dr. Rey, sempre acolhedora, iluminada pelo radiante sorriso de Dora, que sabe envolver seus convidados com pratos de deixar água na boca e uma conversa gostosa, na qual se aprende muito sobre diversas culturas, pois fala delas como quem pôde morar em diferentes lugares e experimentar o verdadeiro estilo de vida de muitos povos. Por toda a casa, objetos dos quatro cantos do mundo revelam a bela e exótica diversidade do artesanato de cada lugar visitado. Destaca-se uma grande peneira onde estão expostas conchas belíssimas, dos mais variados formatos e cores, atestando o interesse do dono pelos moluscos. Entre diversos quadros na parede, uma caricatura do Dr. Rey chama a atenção pela leveza do traço e pela fidelidade ao retratado, parecendo que o desenhista foi capaz de captar-lhe a alma. $\mathrm{O}$ artista? Ninguém menos que um colega seu, Dr. Deane, cuja presença se faz sentida ali.

Em 1988, Dr. Rey tornou-se chefe do Departamento de Biologia do IOC, onde eu trabalhava, e assim pude ter com ele muitas outras conversas. Fui alinhavando a sua trajetória, a qual revela, desde muito jovem, curiosidade

22 REY, L. Contribuição para o Conbecimento da Morfologia, Biologia e Ecologia dos Planorbídeos Brasileiros Transmissores da Esquistossomose. Rio de Janeiro: SNES, 1956. 
e interesse pela investigação. Certa vez contou-nos as suas aventuras da juventude, quando, depois de se formar em medicina e de ter vivido dois anos na Amazônia trabalhando no posto de saúde de Gurupá, decidiu conhecer o país, viajando pelo Brasil afora, experimentando todos os tipos de transporte, seja a pé, a cavalo, de charrete, caminhão, ônibus, barco, canoa etc. Durante mais de dois anos andou pelo interior, praticando a medicina pelo caminho. Parava em alguns lugarejos, trabalhava um pouco e depois seguia viagem. Isso lhe deu uma visão ampla da realidade brasileira, reforçando a sua decisão de trabalhar pela saúde pública.

De volta a São Paulo, tornou-se professor e pesquisador da Faculdade de Medicina da USP, destacando-se no estudo das doenças tropicais. A prinć́pio, dedicou-se ao estudo da fisiologia de parasitas, o que durou pouco tempo, pois logo passou às pesquisas que pudessem conduzir à melhoria de métodos de controle de endemias. Sua preocupação maior era resolver problemas que afligiam a população brasileira, buscando soluções práticas por meio do entendimento das condições ambientais e de transmissão de doenças. Priorizou na época a esquistossomose, doença que causava grandes danos à saúde da população das áreas endêmicas: seu tratamento provocava sérias complicações, devido aos efeitos colaterais dos fortes medicamentos então disponíveis, podendo até levar à morte. O controle também era precário, assim como os métodos de diagnóstico, muito falhos. Havia muito por fazer, e o Dr. Rey dedicou-se com afinco à tarefa. Como professor, uma das características de sua prática pedagógica consistia em levar os alunos ao campo durante as férias, para realizarem inquéritos epidemiológicos em Mato Grosso, no Rio Grande do Sul e em Pernambuco, ligando teoria e prática em saúde pública.

Desenvolvia a sua carreira a todo o vapor, como professor e pesquisador, quando se deparou com uma situação que ele chama de incidental. Era 1964; com o golpe militar, ele, então professor livre-docente da USP, foi enquadrado por um ato institucional, o AI-1, e obrigado a deixar o país. Em 1964, a universidade lutava por sua democratização e moralização, contra 
concursos fraudulentos, luta que passou a incomodar alguns antigos acadêmicos, os quais mantinham as suas cátedras como verdadeiros feudos. Incomodada com a atitude renovadora dos mais jovens, essa ala feudalista aproveitou o momento de ilegalidade política do país e se articulou contra o movimento sadio que ali se instaurava. Os professores acusados entraram com um mandado de segurança, o qual foi recusado pela comissão geral. Assim, ocorreu na USP uma demissão em massa, assinada pelo governador Adhemar de Barros. O caso foi parar na justiça militar, e teve como consequiêncịa a ordem de prisão preventiva dos indiciados, entre os quais achava-se o Dr. Rey, incluído na lista, como tantos outros colegas, por suas conhecidas posições de esquerda. Como integrantes da elite pensante do país, partilhavam dos ideais democráticos, os quais não podiam deixar de defender em suas vidas e em suas aulas. Para se esquivar da prisão, a única saída possível era deixar o país; o México, onde permaneceu por três anos, foi o seu destino. Nos anos que passou no México, deu aulas e fez vários trabalhos de campo com os alunos, orientando e formando pesquisadores.

Ao longo dos três anos de exílio, as coisas foram se atenuando e ele pôde retornar ao Brasil. Ao chegar, foi lecionar parasitologia na Escola de Saúde Pública. Mas, passado apenas um ano de calmaria, novos fatos trouxeram outros momentos difíceis. O então reitor da USP, Gama e Silva, que acumulava o cargo com o de ministro da Justiça, acabou por ser afastado da universidade, a qual elegeu como novo reitor um bom clínico. Gama e Silva, rancoroso, valendo-se do AI-5, montou outro processo contra a USP, no qual incriminava o novo reitor de subsersivo e apontava como prova 0 fato de este ter readmitido os cassados pelo AI-1. Assim, em meados de 70, todos os ex-cassados e mais outros novos professores foram compulsoriamente demitidos. Na ocasião, Dr. Rey, colhido pelo novo golpe, decidiu continuar em São Paulo, escrevendo o livro já iniciado sobre parasitologia e dando consultorias que reforçavam o seu orçamento familiar. Entretanto, começou a circular um boato sobre um plano de troca de intelectuais de esquerda por embaixadores e todos os professores da USP acabaram 
suspeitando de que poderiam estar na mira de tal negociação. E logo ocorreu a prisão de um dos professores, o parasitologista Erney Camargo, da equipe do Prof. Samuel Pessoa, tal como o Dr. Rey. Havia cerca de nove ou dez professores no grupo do Prof. Samuel, e todos foram enquadrados. O próprio Prof. Samuel ficou durante um bom tempo 'escondido' na Bahia, evitando assim tornar-se prisioneiro. Tão logo o Prof. Erney foi preso, sua esposa ligou para a Dora e perguntou se o Dr. Rey estava bem. Dora respondeu que sim e perguntou pelo Erney. A resposta negativa seguida pelo desligamento abrupto do telefone foi suficiente para dar o alarme. Desconfiaram do acontecido e Dr. Rey então seguiu imediatamente para o Rio, pois teve receio de ser preso no aeroporto de São Paulo. No dia seguinte seria feriado militar, dia de Tiradentes. Não poderia esperar, vislumbrava a possibilidade da prisão iminente e, assim, aproveitou o feriado, arrumouse às pressas e embarcou para Genebra, pois já estava negociando um contrato com a OMS. Acabou assinando um contrato por quatro anos, indo primeiramente trabalhar na Tunísia, onde se dedicou ao desafio de controlar a esquistossomose.

Era uma situação desafiadora, tanto em termos intelectuais quanto científicos, não lhe restando qualquer possibilidade de fracassar. Enfrentou com garra a adversidade que se punha em seu caminho e acabou por permanecer no exílio durante 18 anos. Um período produtivo em que pôde contribuir para o controle de endemias e para a formação de profissionais na África e na América Latina.

Na Tunísia, desenvolveu uma metodologia que possibilitou não só controlar, mas erradicar a esquistossomose, um caso exemplar na literatura da área. Lá, a doença era causada pelo Schistosoma haematobium, verme responsável por uma forma urinária de esquistossomose, transmitido ao homem por caramujos do gênero Bulinus, presentes nas águas de numerosos oásis. Dr. Rey conta como foi importante estudar as características ecológicas da região, conversar com a população e fazer observações culturais antes de preparar o plano de controle. Logo que chegou, pensou em deixar as 
moças no laboratório e enviar os rapazes às casas das famílias das regiões endêmicas para coletar o material necessário aos exames. Mas um nativo explicou a ele que isso não funcionaria. Seria melhor enviar um casal, pois se o dono da casa estivesse, era o rapaz quem deveria falar com ele, que não atenderia uma mulher. E na ausência do chefe da família, se o rapaz chegasse sozinho ninguém viria abrir a porta, pois as mulheres são proibidas de se dirigir a qualquer homem estranho. Assim, a moça falaria com elas. Um outro problema surgiu nas viagens para o campo, onde fariam o tratamento dos doentes e aplicariam moluscicidas nos criadouros. Pois bem, os funcionários que vinham da capital, Túnis, acompanhando o Dr. Rey pediam com freqüência licença para retornar a suas casas, o que tornava difícil fixálos nas áreas endêmicas. Dr. Rey, percebendo o problema, logo aceitava a transferência e pedia a substituição do funcionário por algum morador do próprio local. Essa foi uma das estratégias que colaboraram para o sucesso do programa, evitando a descontinuidade das ações de controle e facilitando o processo educativo, que se realizou sem barreiras culturais e lingüísticas. Segundo conta, ao voltar lá, mais de vinte anos depois, encontrou as mesmas pessoas que contratara, mantidas nos serviços. Ficou na Tunísia por quatro anos e a partir de 1972, 1973, sua estratégia de controle já se fazia sentir, interrompendo a transmissão da doença. Em 1974, o governo e a OMS viam o problema como resolvido, e o que restava como resíduo era passível de controle com os recursos do próprio governo. Depois disso, ocorreu apenas um surto localizado em 1982, em um último foco ativo de esquistossomose de uma região circunscrita da Tunísia.

Ficou também seis anos em Genebra, como funcionário da OMS, prestando assistência a países da África, América do Sul e Ásia. Em Cabo Verde realizou controle de helmintoses e implantou um plano nacional de saúde. Em Moçambique, dirigiu e organizou o Instituto Nacional de Saúde. Em outros locais, como na Jordânia e na Tunísia, realizou controle específico de esquistossomose. Na Jordânia, a doença era espalhada por trabalhadores vindos do Egito. Os focos de transmissão podiam ser encontrados ao longo 
do vale do Rio Jordão e nas piscinas romanas alimentadas por águas naturais. Os caramujos transmissores eram do gênero Bulinus. Dr. Rey desenvolveu estratégias de controle, buscando transferir o conhecimento adquirido nos anos de pesquisa em laboratório para a atuação prática no campo. Realizou também na Argentina um plano de vigilância epidemiológica nos lagos artificiais construídos para produção de energia. Em Moçambique, o seu plano foi interrompido pela guerra.

Dr. Rey insiste em que, além dos aspectos técnico-científicos, são as decisões de alto nível político e administrativo as melhores garantias de êxito em um programa de saúde. Na Tunísia, a decisão governamental de melhorar a economia do país desenvolvendo o turismo foi a base do sucesso do programa para controle da esquistossomose, da malária e de outras endemias que inviabilizavam os projetos turísticos.

Pensando no propósito deste livro, Dr. Rey relembrou, além de sua história, vários fatos interessantes da ciência, como o hiato entre a descoberta da penicilina, em 1938, e sua redescoberta durante a Segunda Guerra Mundial, por necessidade. Citou a cromatografia, um princípio descoberto há séculos e só tardiamente aproveitado, um caso típico de anacronismo, ou seja, a descoberta antecedendo a necessidade e o uso efetivo. Atrasos também se devem a barreiras de comunicação, como ocorreu com o enunciado das leis de Mendel, pois o matemático publicou seus achados em tcheco, língua que dificultou a divulgação da descoberta. A dificuldade de comunicação no meio científico resulta em atraso no desenvolvimento e na aplicabilidade da ciência. Outras vezes, algum interesse particular de alguém que esteja no poder favorece descobertas. Dr. Rey cita o exemplo de Roosevelt, que, por ter sofrido atrofia muscular causada pela poliomielite, quando tornou-se presidente dos Estados Unidos forneceu as verbas abundantes que garantiram o desenvolvimento e o sucesso da pesquisa da vacina antipólio.

A história do Dr. Rey nos mostra como uma absurda situação de perseguição política, fruto do ambiente adverso do Brasil, o projeta para o 
exílio, onde se transforma numa personalidade internacional na área da saúde pública e contribui para a melhoria da saúde em vários países de outros continentes. Ele soube transformar uma circunstância desfavorável em uma oportunidade de exercer com brilhantismo a sua profissão e dignificar o nome do próprio país que o mandou para o exílio. 


\section{Luís Rey ${ }^{23}$}

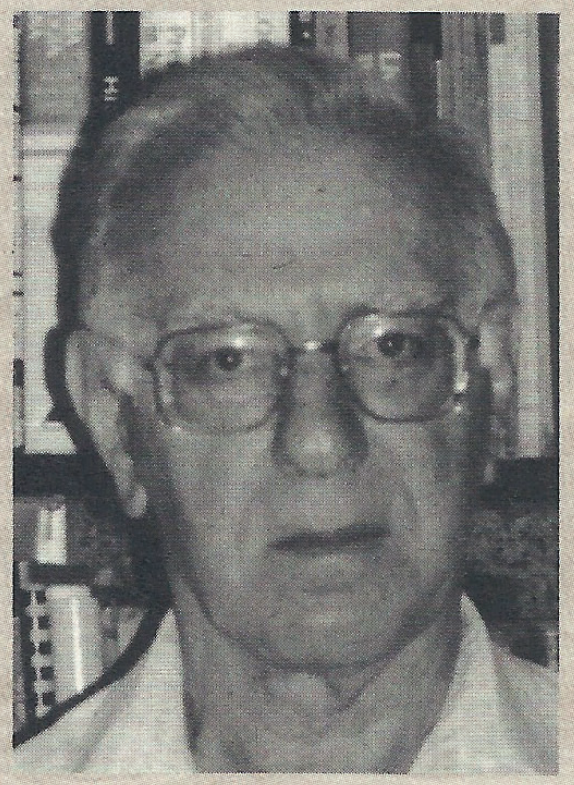

Dr. Luís Rey nasceu em São Paulo, SP, no ano de 1918. Formou-se em medicina em 1944, na USP, tendo iniciado sua carreira como chefe de um posto de saúde do SESP, na Amazônia. Especializou-se em saúde pública pela École Nationale de Santé Publique, em Paris, nos anos de 1948 e 1949. De volta ao Brasil, trabalhou na Divisão de organização Sanitária do então Ministério da Educação e Saúde, no Rio de Janeiro. Em 1951 tornou-se professor de parasitologia da Faculdade de Medicina da USP, São Paulo, onde doutorou-se em 1956 e obteve o título de livredocente de parasitologia (1961). Fundou a Revista do Instituto de Medicina Tropical de São Paulo, e foi seu editor até 1964. Foi também professor de parasitologia no México, na Escuela Nacional de Ciencias Biológicas do Instituto Politécnico Nacional, de 1965 a 1967; na Faculdade de Higiene e Saúde Pública da USP, de 1968 a 1969; na Faculdade de Medicina da Universidade do Norte do Paraná em 1969; na Faculdade de Medicina de Taubaté, SP, de 1968 a 1969; e na Faculdade de Medicina da Universidade Eduardo Mondlane, em Maputo, Moçambique, de 1980 a 1983. Foi contratado pela OMS para realizar, de 1970 a 1974, um programa de controle da esquistossomose na Tunísia, onde conseguiu eliminar a endemia. Em seguida transferiu-se para a Divisão de Malária e Doenças Parasitárias, em Genebra, onde

\footnotetext{
${ }^{23}$ Extraída do livro REY, L. Parasitologia. Rio de Janeiro: Guanabara Koogan, 1991, e do memorial cedido pelo autor (2000).
} 
trabalhou de 1974 a 1980. Realizou numerosas missões como membro da WHO Expert Advisory Panel on Parasitic Diseases: General Parasitology; foi consultor da OMS e da Organização Pan-Americana de saúde (Opas) para os serviços nacionais de saúde de países da América Latina, do Médio oriente e da África. Aposentado em 1980, continuou a ser consultor da OMS, tendo sido coordenador do Instituto Nacional de Saúde de Moçambique, de 1980 a 1983, organizando e orientando programas de controle de endemias no país. como pesquisador titular da Fiocruz a partir de 1984, foi chefe do Departamento de Helmintologia de 1984 a 1985 , diretor do Instituto Nacional de controle de Qualidade em Saúde (INCQS) de 1985 a 1989, e chefe do Departamento de Biologia de 1989 a 1991, quando foi aposentado compulsoriamente pelo governo, por força de uma lei que incluiu todos os profissionais de mais de 70 anos. A partir de 1991, foi recontratado por DAS (cargo comissionado) como chefe do Laboratório de Biologia e Controle da Esquistossomíase, por ele criado em 1985 no Departamento de Medicina Tropical do 10C. Foi presidente da Sociedade Brasileira de Parasitologia de 1987 a 1989. Tem mais de cinqüenta trabalhos publicados em revistas científicas e é autor de vários livros, como: Parasitologia (731p.), já na $2^{a}$ edição; Planejar e Redigir Trabalhos Científicos (318p.), $2^{a}$ edição; e Dicionário de Termos Técnicos de Medicina e Saúde (825p.), pelo qual recebeu da Câmara Brasileira do Livro o Prêmio Jabuti de melnor obra na área de ciências da natureza e ciências da saúde publicada em 1999. 